\section{Budgeting for Griffiths}

\section{JOHN S S STEWART}

The Griffiths report, which was initially received by the profession with guarded optimism, presents an interesting challenge to National Health Service management. ${ }^{1}$ The report was supported by the Hospital Consultants and Specialists Association in the expectation that it would herald a return to a simpler and more accountable system of management, ${ }^{2}$ but the reception was lukewarm from the Central Committee for Hospital Medical Services, where concern was expressed about the short consultation period, ${ }^{3}$ and was even more guarded when the BMA council met, when many reservations were expressed and incorporated in the association's response. ${ }^{4}$

It is at unit level that the recommendations of Mr Roy Griffiths and his colleagues would make most impact on consultants, for the intention is that clinicians should participate more closely in management, consistent with freedom for clinical practice. General management is defined in the report as "the responsibility drawn together in one person at different levels of the organisation for planning implementation and control of performance." Management is required to ensure that "responsibility is pushed as far down the line as possible, that is to the point where action can be taken effectively." The importance of information is emphasised: "Clinicians need administrative support, together with strictly relevant management information, and a fully developed management budget approach."

As to the importance of having doctors as general managers, the report states: "The nearer that the management process gets to the patient, the more important it becomes for the doctors to be looked upon as the natural managers." On the question of increasing efficiency or making savings the report is more specific: "Line management should be free to determine how to achieve this drawing on established management techniques and recent developments in audit." It again emphasises the participation of clinicians: "We believe that urgent management action is required, if units are to fulfil their role and provide the most effective management of their resources. This particularly affects the doctors. Their decisions largely dictate the use of all resources and

\section{Royal Albert Edward Infirmary, Wigan,} Lancashire

JOHN S S STEWART, BSC, FRCS, consultant general surgeon they must accept the management responsibility which goes with clinical freedom. This implies active involvement in securing the most effective use and management of all resources."

\section{Implications for clinicians}

The Griffiths report is a much needed analytical review of NHS management. The general recommendations seem sound but they need clarification. Industry is usually organised as a pyramidal structure, with workers on the shop floor forming the base of the pyramid and the managing director placed at the apex. In hospitals the position is different: every consultant is a managing director but he also works on the shop floor. General managers have been identified at region, district, and unit level, but line management must go further. At the end of the line is a consultant manager who could spare some time for resource management without serious loss of clinical skills. This is implied by the Griffiths report, which explicitly recognised that the system of management budgets must meet the medical requirement and interest. The implied continuation of line management to divisional or to individual consultant level must, however, be made explicit. In addition other requirements must be met.

Little information about NHS costs has hitherto been available. Yet information is a necessary prerequisite for any form of budgeting, and if budgeting is to be successful it is essential that the information on which the decisions are based is accurate and reliable. In addition, it is important that any associated book keeping should be simple, but considerable computation will be required because there are many data. These requirements can be met only if a computer based information system is used. It is imperative, however, that the confidence of the medical and nursing professions is obtained and that confidentiality is maintained.

Anxiety about confidentiality may best be dispelled by giving each consultant full responsibility for, and control over, the data arising from patients under his care. Any link up with regional based or other large computer installations should be restricted. Print outs of case notes that are identified only by a reference number, with similarly restricted identification of computer based data for financial or other analysis by general managers, should be acceptable. Confidence would further be enhanced if unauthorised access is prevented by using suitably designed software. Patient confidentiality must be guaranteed, and this could be done if consultants have control over data security.

The recommendations of the Griffiths report imply a greater degree of clinical audit than has so far been accepted by the profession. Such audit might be acceptable but only if it is restricted to clinicians in the relevant firms and divisions-that is, if it is carried out by peer review. Clinical control of the data would also ensure that this condition is met.

Management has been defined as including planning, implementation, and control. Clearly, planning should be carried out in consultation with other interested parties, notably the district management team at district level and the director of nursing services at unit level. After agreement the plan may be implemented, but the last function-control-implies that the consultant manager has the power and authority to increase or restrict resourcesincluding staff, facilities, and services-within the overall limits of his budget. For management to be effective, responsibility must be supported by appropriate powers.

\section{New technology}

It has been said that adequate information can be obtained only if computer technology is used, and the impact of this on clinical work must be considered.

New computer technology must be acceptable to nursing staff and acceptability would be enhanced if a computer was seen to be useful in patient care. The provision of computer produced nursing records could be an important inducement to encourage participation by the nursing staff. The benefits of computerised stock control with reduction of manual paperwork could well be attractive to a busy ward sister because she could devote more time to her primary interest-nursing patients.

Data collection on the ward by interactive computing-interaction between operator and computer-is considered to be the best method. This system would ensure that information is reasonably accurate, and if the nursing staff were motivated to use the computer additional clerical staff would not be required to collect the data. Initially, data input would be at a terminal with a visual display unit and keyboard. Later, when some requirements have been more precisely defined, a light pen and bar code reader input would simplify participation and would probably be more cost effective.

Advances in technology have resulted in smaller, cheaper computers and their use is becoming widely popular because of their greater flexibility and user friendliness and the availability of high level computer languages. Doctors favour microcomputers rather than minicomputers or main frame computers because apart from their convenience they offer better data security, which should help to allay the profession's fears about confidentiality, fears that have been publicly expressed during the passage through parliament of the government's legislation on data protection ${ }^{5} \mathrm{~A}$ microcomputer sited in and serving a single ward or firm is as secure and confidential-probably more so-as existing medical records based on handwritten case notes. Thus, a microcomputer based system is preferred on the grounds of flexibility, medical acceptability, and cost. 


\section{Type of costing}

The type of costing employed and its accuracy is important, but opinion is divided about the method to be used. The Körner report was concerned with improving financial information for management. ${ }^{6}$ The Körner committee considered, among others, two main possibilities-patient costing and specialty costing. It rejected the former because the information would be too expensive to collect: the committee preferred specialty costing because it was thought to be cost effective. The Griffiths report, however, implies the opposite conclusion.

Specialty costing is based on crude apportionment of costs, a system unacceptable to clinicians, who are used to precise information in diagnosing and treating patients. Similar precision will be expected in relation to financial costing. Thus, if clinicians are to have confidence in accounting procedures these must include accurate calculations of items of service and of consumables used rather than approximations.

The benefit of patient costing is that it provides full data on which precise information may be based. Clinical efficacy cannot be measured unless several factors are considered. Information must be provided about the number of cases treated and the complexity of each case-for example, whether an operation was major, intermediate, or minor. Information must also be provided about the optimal investigative pathway used to achieve a diagnosis-that is, the employment of the cheapest tests consistent with patient safety and of the fewest tests consistent with precise and accurate diagnosis. All this is relevant management information and is required to meet medical needs and interests. This is what the Griffiths report has promised, and it contradicts a principal conclusion of the Körner committee.

The importance of patient costing lies in its relation to clinical audit. If patient costing is not available then audit is bound to revolve round the complexity of the cases treated. Discussion would be seriously limited since the use of specialty costing would mean that the necessary information was not available. The Körner committee recognised the superiority of patient costing but preferred specialty costing only because collecting the information for the former system was judged to be too expensive. With the introduction of automatic data collection at ward level, however, this drawback should disappear as patient costing would become cost effective.

\section{Discussion}

A budget implies the setting of objectives within certain cost limits, and a review by Wickings ${ }^{7}$ of clinical budgeting and costing experiments is a useful contribution to the debate on how best to manage the health service's resources.

Experiments with clinical costing ${ }^{1}$ have been a failure, and little or no change in clinical practice resulted from presenting costing data to clinicians. In particular, a dispute arose about the value of the so called "norm." The narrowing of acceptable ranges could well discourage experimentation and lead to the fossilisation of medical procedures. ${ }^{8}{ }^{9}$ This view was not, however, shared by others, who considered that below average costs might be associated with greater efficiency and better medical standards. ${ }^{1011}$

Experiments have been much more successful with clinical budgeting, when the clinician is concerned with managing the budget and is not merely a recipient of costs or of costings produced by someone else. It is probable that this method could produce significant savings. 1213

Accurate information is essential for accurate costing. It is generally accepted that such information as is available from Hospital Inpatient Activity Analysis ${ }^{14}$ and performance indicators do not give the necessary information. ${ }^{15}$ Information is much more reliable in the King's Fund projects on clinical accountability, service, planning, and evaluation in the NHS, but the cost of collection is substantial and its accuracy may depend on the dedication of research staff.?

To return to clinical audit, the implications of the Griffiths report are entirely clear to Day and Klein, who state that "it makes no sense whatsoever to talk about evaluating the performance of the NHS without also insisting in evaluating the performance of those who take the most important decisions about the use and allocation of resources to individual patients: doctors."15 These authors consider that such questions must be the subject of peer review, "while leaving it to the doctors concerned to exercise their peer group judgment as to how that performance could be improved." Dyson, on the other hand, sees clinical freedom as the problem, arguing that direction about clinical matters should be imposed on the profession: "If clinical freedom is to be reduced to, say, the level at which it exists in many hospitals in the United States, consultants' contracts should be held at district with tenure limited to three or five years, renewable only after assessment of clinical performance in relation to resources used."17

The primary objective of clinical staffdoctors and nurses-is to care for and to protect the interests of the patients. This is why clinical freedom is so important. Patients need protection from others who wish to reduce costs by reducing standards, and that means reducing safety for patients. Protection is needed from the actions (however well intentioned) of politicians, economists, health authority chairmen, and, perhaps in the future, general managers as well.

How do those outside the profession look at clinical freedom? As stated already, Dyson strongly favours restricting it, ${ }^{17}$ but Wickings equally strongly opposes any interference. ${ }^{18}$ For the purposes of clinical budgeting it is largely irrelevant for there is no objection to clinical audit by peer review. As Chawner has pointed out, there is no objection to asking questions such as, "why, say, a hysterectomy costs twice as much in one district as in another comparable one, and a consultant who keeps his patients in hospital much longer than average should be asked to justify his decision."14 But these questions cannot be answered unless patient costing and patient management information is available.

There is much more agreement about management budgets. Even Dyson agrees that, "Effective budgetary responsibility must be brought as near to the individual clinician as possible." 17 Thus, inexorably, we return to the importance of accurate information relating to individual patients, to the cost of collecting it, and to the acceptability of the method of collection to the medical and nursing staff.

The NHS has suffered from reorganisations that many doctors believe have done more harm than good. The service also suffered from the hasty introduction of proposals for senior nursing staff structure. ${ }^{19}$ So it is understandable that the Griffiths proposals were received with caution and calls for more extended trials. ${ }^{4}$

\section{Conclusion}

Administrative support for clinicians is necessary to ensure that they do not waste time on non-clinical matters. The clinicians can then get on with the NHS's prime function: treating patients.

Clinicians should have the powers necessary to control their budgets and line management should be extended to divisional or individual consultant level.

Management information must be accurate, strictly relevant, and sufficiently detailed to meet medical requirements and interests. Thus, patient costing is essential.

Information should be collected by interactive computing and the computer stored data must be under the direct control of individual clinicians to ensure that the requirements of patient confidentiality and audit by peer review are met.

If these conditions are accepted clinicians would probably be willing to help the NHS attain the objectives desired by Griffiths-to achieve the best service possible for patients, to obtain the best value for the taxpayer, and to achieve the best motivation for staff. The first priority, however, must be the best possible service for patients within available resources. Even so, before the general introduction of Griffiths type budgeting to the NHS is considered there must be properly evaluated pilot projects. Otherwise, the NHS could be subjected to further upheavals that result in no discernible advantage to patients or staff but are costly to the taxpayer.

I thank Wigan Health Authority for research facilities I thank Wigan Health Authority for research facili
and Mrs Joan Hartley for typing the manuscript.

\section{References}

1 NHS Management Inquiry. Report. London: DHSS, 1983. (Griffiths report.)

2 Ryall R. Consensus and the general manager. The Consultant 1983;7:5.

${ }^{3}$ Anonymous. Lukewarm reception for Griffiths report. Br Med f 1983;287:1811-2.

Anonymous. Griffiths inquiry: BMA writes to minister. Br Med f 1984;288:165.

5 House of Commons. Data Protection Bill, second reading. House of Commons Official Report (Hansard) 1984 January 30;53:cols 30-105. (No 87.)

6 National Health Service and Department of Health and Social Security Steering Group on Health Services Information. First report. London: DHSS, 1982.

7 Wickings I, Coles JM, Flux R, Howard L. Review of clinical budgeting and costing experiments. Br Med f 1983;286:575-8.

${ }^{8}$ Gillespie IE. Budgets for clinicians. Desirable and/or practical? Hospital and Health Services Review 1979;75:428-31.

${ }^{9}$ Bartlett JR, Neil-Dwyer G, Penney CC, Harwood G. Should doctors be budget holders ? $\mathrm{Br}$ Med 7 $1981 ; 283: 450-4$.

10 Magee C. The potential for specialty costing in the NHS. Public Finance and Accountability March 1981:41-4. 
11 Harper D. Comparative disease costing in surgical practice. In: Hospital costing and the clinician. London: DHSS, 1978:15-22.

12 Wickings I. Incentives, budgets, and planning arrangements for clinical teams. In: Hospital costing and the clinician. London: DHSS, 1978:23-6.

13 Gibberd FB. The clinical accountable team. Health Trends 1982;14:43-5.

14 Chawner JRA. The consultant's role in NHS management. $\mathrm{Br}$ Med 7 1983;287:1816-8.

15 Anonymous. From the JCC. Br Med F 1983; 287:1396.

${ }^{16}$ Day P, Klein R. The mobilisation of consent versus the management of conflict: decoding the Griffiths report. $\mathrm{Br}$ Med $\mathcal{f}$ 1983;287: 1813-6.

17 Dyson R. Griffiths inquiry: a personal perspective. Br Med F 1984;288:255-7.

18 Wickings I. Consultants face the figures. Health and Social Services fournal 1983; 8 December:1466-8.

19 Committee on Senior Nursing Staff. Report. London: HMSO, 1966. (Salmon report.)

\section{Medical academic staff}

\section{"Worrying aspects" of UGC's strategy}

The University Grants Committee's strategy for higher education into the 1990s, the General Medical Council's proposals for basic specialist training, and honorary contracts and manpower planning were all discussed by the medical academic staff committee at its meeting on 17 February.

The committee considered the letter-dated 1 November 1983-that the chairman of the University Grants Committee had sent to vice chancellors and principals of United Kingdom universities on the development of a strategy for higher education into the 1990s. Professor J P Payne had drawn attention to this in a letter in the $B M \mathcal{F}$ (28 January, p 329), criticising the fact that from his own inquiries it seemed that medical academic staff had not been informed about the "wide ranging and open debate [on a strategy for higher education] that the Secretary of State for Education and Science is said to be seeking."

Other points made by Professor Payne in his letter were:

- "In clinical medicine 2943 teachers were in post in 1980-1 and the projected number for $1984-5$ is 2521 , a reduction of 422 or $14.3 \%$. This percentage reduction in the number of clinical teachers is among the highest in the university system; what is worse, the greatest reduction, from $24 \%$ of the total to just under $16 \%$, is in the age group $30-34$ years, from among whom the future academic leaders would normally be expected to emerge during the next decade.

- "Unlike the student intake of most other faculties, which can be tailored to meet the availability of teachers and other resources, the medical school intake is controlled by government and it is current government policy that the medical student intake will remain unchanged or may even be increased during the next five years. Thus a $14 \%$ reduction in the number of teachers without a corresponding reduction in the number of students may well lead to a lowering of standards.

- "I do not believe that it is the task of academic staff to make it easier for government ministers to avoid the consequences of their own decisions.

- "The universities are at least as vital to the future welfare of this country as are the armed services, and they deserve the same degree of financial protection. If the minister thinks otherwise then he should enforce his policy

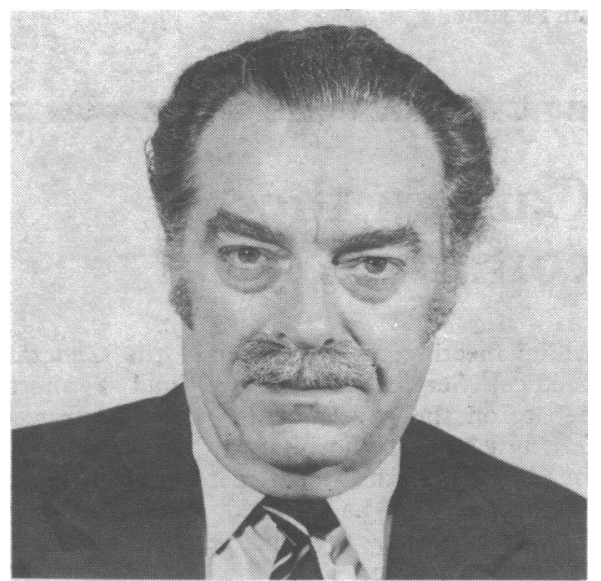

Professor J P Payne, chairman of the medical academic staff committee.

through his department and not attempt to use the University Grants Committee for this purpose.

- "The chairman of the University Grants Committee is asking the wrong questions [in his circular letter]. He should be seeking information from the universities about how best to protect the quality of university education and should be directing to the Secretary of State the questions that will elicit clearly, without ambiguity, the minister's objectives."

Dr C L Smith suggested that apart from a general response from the BMA the committee should consider writing to the new chairman of the medical subcommittee of the University Grants Committee, Professor Colin Dollery, because of his special responsibility for medical staff. There were several worrying aspects. Firstly, there would be a cut in staff if the proposals were implemented. The main cut was in the under 35 age group. No new junior staff would be taken on as time went on It was already impossible to fulfil teaching requirements laid down by the General Medical Council in some disciplines as a result of the last cuts. There were not enough pathologists in some schools to fulfil requirements. If there was a further $1 \%$ reduction in medical staff it would mean that some medical schools would have to cut up to $40 \%$ of their student intake. Dr Smith thought that the document was appalling for the future of medical education.

The committee agreed that the chairman should write to Professor Colin Dollery, that the matter should be raised in the BMA council, that an approach should be made to the General Medical Council, and that every means should be sought to ensure that the subject was widely discussed.

\section{Basic medical training}

The General Medical Council had invited comments on its proposals on basic medical education (12 November 1983, p 1487). Dr C L Smith said that the proposals seemed to ignore the fact that the training period could be 14 years in surgery and in some cases 16. If a further two years were added it could be 18 years before a doctor reached a consultant job. In other disciplines, such as radiology, where there was an accelerated course, the proposal could be incorporated, but there was no suggestion as to how a broad based curriculum of postgraduate education should be implemented. No guidance had been given about a combination of specialties, but it was said that it should include six months' general practice. There were not enough posts in general practice to accommodate all the people who would need to go through the specialty. The document's ideals were excellent, but Dr Smith suggested that implementation was bereft of logic and practicality. The GMC should be asked for guidance on how the proposals could be implemented.

As a regional adviser in general practice Dr S E Josse said that it was the first time that he had seen anyone put forward the idea that junior posts should be reserved specifically for non-career aspirants for the specialty.

\section{Honorary contracts}

A mechanism had been agreed between the Department of Health and Social Security, the Joint Consultants Committee, the Medical Research Council, and the universities for limiting the numbers of honorary senior registrar posts (18 February, p 581).

Dr C L Smith said that the scheme applied to clinical and preclinical staff and envisaged the inclusion of all honorary contracts in the total manpower numbers. The numbers would be in a quota for each region-a quota for senior registrars and honorary senior registrars administered by a committee in the region. Those people who went for honorary contracts outside that quota would get not an honorary senior registrar contract but an (as yet) undecided contract that might be a clinical assistantship. Dr Smith said that the number of honorary contracts that would be made available in the first round of quotas might well restrict the honorary senior registrar contract to those "tenured posts" already existing in medical schools. The Department of Health and Social Security was not clear what "tenured" meant. What it meant was established posts and not "tenured" posts. If quotas were introduced there would be no room without special dispensation for the appointment of lecturers with honorary senior registrar contracts in developing specialties in a university medical school-for example, molecular biology. There was a bland assumption, particularly in the Central 